\title{
A MODEL CALCULATION OF TRANSPORT COEFFICIENT FOR SMALL NEGATIVE IONS IN THE TROPOSPHERE
}

\author{
K. I inuma \\ Department of Quantum Science and Energy Engineering, \\ Tohoku University, Sendai 980-77, Japan
}

\begin{abstract}
Drift velocities and diffusion coefficients of 30 small tropospheric negative ions are calculated by collision integrals using the $(\mathrm{exp}, 4)$ core potential at altitudes of $0.0 \mathrm{~km}, 5.0 \mathrm{~km}$, and $10.0 \mathrm{~km}$. The ions are classified into three groups; $\mathrm{NO}_{3}{ }^{-}$ion clusters, $\mathrm{HSO}_{4}{ }^{-}$ion clusters, and some negative hydrocarbons. Five sets of two potential parameters, the steepness and the normalized rigid core radius, are employed for these ion/air combinations. Calculated mobilities of $\mathrm{NO}_{2}^{-}$and $\mathrm{NO}_{3}^{-} \cdot\left(\mathrm{H}_{2} \mathrm{O}\right)_{n}(\mathrm{n}=$ $0,1,2)$ are compared with their experimental values, and we find that the agreement is excellent. Based upon the theory of dynamic equilibrium of reactive ion transport, a pair of formulae to determine the ion/molecule reaction rate of tropospheric negative ions is proposed and applied for the analysis of $\mathrm{HSO}_{4}^{-} \cdot\left(\mathrm{HNO}_{3}\right)_{n}$ ion-cluster family $(\mathrm{n}=1,2)$.
\end{abstract}

\section{Introduction}

In situ observation of ion compositions in the troposphere by modern mass spectrometry has revealed the presence of two major negative ion cores, $\mathrm{NO}_{3}{ }^{-}$and $\mathrm{HSO}_{4}{ }^{-}$, and their ion cluster families (Heitmann and Arnold, 1983; Eisele, 1989). These ion clusters, which are produced by ion/ molecule association reactions, are, in general, composed of the ion core and several $\mathrm{H}_{2} \mathrm{O}, \mathrm{HNO}_{3}$, and $\mathrm{H}_{2} \mathrm{SO}_{4}$ molecules. The rate of these reactions is mainly, controlled by mean relative translational energy between an ion and those trace amount of atmospheric molecules. The ions gain the energy from the electric field generated in the troposphere (Wahlin, 1994). Therefore, the transport coefficient (drift velocity and diffusion coefficient) of ions has a position as a fundamentally important quantity for elucidating the tropospheric ion chemistry. However, for most of the large negative ion clusters, no transport data is available at present both experimentally and theoretically. Experimental difficulty in Ion Mobility Spectrometry (IMS) may arise from their extremely small bond dissociation energies (for example, Radzig and Smirnov, 1985). From theoretical standpoint, no appropriate and versatile interaction potential model between an ion cluster and an (effective) air molecule has been established for the calculation of collision integrals (Mason and McDaniel, pp. 226-229, 1988).

Recently, we have developed an (exp,4) core potential model (I inuma and Nishikatsu, 1997) to calculate the drift velocities and diffusion coefficients of 30 positive ions, which have been identifed in the troposphere during the last decade. Comparing those with some experimental transport data, this potential has been proved to be useful for small ion cluster/ air molecule combinations. Based upon the same numerical method, we calculate the drift velocities and diffusion coefficients of 30 tropospheric negative ions. The present paper reports them at altitudes of 0.0 $\mathrm{km}, 5.0 \mathrm{~km}$, and $10.0 \mathrm{~km}$. Also, it is shown that those transport coefficients enable us to derive the rates of ion/molecule reactions by making use of dynamic equilibrium condition, which probably governs the tropo- 
spheric ion chemistry (Iinuma et al., 1993).

2. Theoretical model

Present method of numerical calculation to obtain drift velocity and diffusion coefficient of ions has been precisely reported in the previous paper (Iinuma and Nishikatsu, 1997), and will be only outlined here.

The potential model proposed as a function of separation distance $r$ is represented by

$$
\left\{\begin{array}{cc}
V(r)=\frac{4 \varepsilon}{k-4}\left[\mathrm{exp}\left(\frac{\mathrm{k}\left(\mathrm{r}_{\mathrm{m}}-\mathrm{r}\right)}{\mathrm{r}_{\mathrm{m}}-\mathrm{a}}\right)\right. \\
\left.-\frac{\mathrm{k}}{4}\left(\frac{\mathrm{r}_{\mathrm{m}}-\mathrm{a}}{\mathrm{r}-\mathrm{a}}\right)^{4}\right] & \mathrm{r} \geqq \mathrm{r}_{\max } \\
\mathrm{V}(\mathrm{r})=\infty & \mathrm{r}<\mathrm{r}_{\max }
\end{array}\right.
$$

where $\varepsilon$ is the depth of potential minimum, $r_{m}$ is the position of the potential minimum, and $k(>4)$ and $a^{*}\left(=a / r_{m} ; 1 \geqq a^{*} \geqq 0\right)$ are its steepness factor and the normalized rigid core radius, respectively. The $r_{\max }$ is the value of $r$ at a spurious maximum of $V(r)$. Then, the true reduced core radius of $V(r), b^{*}$, is defined by $b^{*}=r_{\max } / r_{m}$. This potential model consists of a repulsive term of exponential type and an attractive term of $\mathrm{r}^{-4}$ type, including a rigid core radius in it. For physicochemical study of gaseous ions presented in the atmospheric environment, this model appears to be more realistic than the Lennard-Jones potential as well as its some modified versions such as Buckingham-Corner potential (Hirschfelder et al, , 1964) etc.

The reduced collision integral $\Omega^{*}$ as a function of reduced effective temperature $T_{\text {eff }}^{*}$ (Mason and McDaniel, pp. 226-229, 1988; I inuma and Nishikatsu, 1997) can be calculated from this potential by numerical integration method. The reduced mobility (the value reduced to S.T.P. condition) of singly charged ion in air is expressed in terms of $\Omega^{*}$ as

$$
K_{0}=\frac{5.469 \times 10^{-3}}{\left(\varepsilon r_{m}^{4} M_{I M} T_{e f f}^{*}\right)^{1 / 2} \cdot \Omega^{*}\left(T_{\text {eff }}^{*}\right)}
$$

where $M_{I M}$ is the reduced mass of an ion and an effective air molecule (= 28.97amu; Warneck, 1988). The units employed are $\mathrm{K}_{0}$ in $\mathrm{m}^{2} \mathrm{~V}^{-1} \mathrm{~s}^{-1}, \varepsilon$ in eV, $r_{m}$ in $\AA, M_{I M}$ in amu, and both $T_{\text {eff }}^{*}$ and $\Omega^{*}$ are dimensionless quantity. Making use of the $\mathrm{K}_{0}$ in Eq. (2) and the Nernst-Townsend-Einstein relation (Mason and McDaniel, pp. 138-139, 1988), the drift velocity $U$ and the diffusion coefficient $D$ are represented as 


$$
\begin{aligned}
& \mathrm{U}=2.6868 \times 10^{4} \cdot \mathrm{K}_{\mathrm{O}} \cdot \mathrm{E} / \mathrm{N} \\
& \mathrm{D}=2.3153 \times 10^{21} \cdot \mathrm{K}_{0} \cdot \mathrm{T} / \mathrm{N}
\end{aligned}
$$

where $E, N$, and $T$ are the electric field strength, the air number density, and the air temperature, respectively. The units are $U$ in $\mathrm{ms}^{-1}$, $\mathrm{D}$ in $\mathrm{m}^{2} \mathrm{~S}^{-1}, \mathrm{~T}$ in degrees Kelvin, and $\mathrm{N}$ in $\mathrm{m}^{-3}$, while the ratio $\mathrm{E} / \mathrm{N}$ in Eq. (3) employs the units of "Townsend" $\left(1 \mathrm{Td}=10^{-21} \mathrm{Vm}^{2}\right)$. The value of $\mathrm{E} / \mathrm{N}$ can be obtained from the theory of atmospheric electricity developed by Wåhlin (1994) and the data of U. S. Standard Atmosphere (Warneck, 1988).

3. Results and discussion

The values of $N, T$, and $E / N$ employed for the present calculations are listed in Table 1. Five sets of ( $\left.\mathrm{k}, \mathrm{a}^{*}\right)$ combinations in Eq. (1) are determined appropriately for 30 negative ions; $(17,0.07),(16,0.12),(16$, $0.15),(15,0.18)$, and $(14,0.20)$, by taking into account the differences of their molecular weight and their chemical forms. The corresponding values of $b^{*}$ are $0.10531,0.16175,0.19033,0.22881$, and 0.26002 , respectively.

Table 1. Number density and temperature of air, and $\mathrm{E} / \mathrm{N}$ at $0.0 \mathrm{~km}, 5.0 \mathrm{~km}$, and $10.0 \mathrm{~km}$. The values of $\mathrm{E} / \mathrm{N}$ are obtained from Wåhlin's theory

(Wåhlin, 1994).

\begin{tabular}{|cccc|}
\hline & $\mathrm{N}\left(\mathrm{m}^{-3}\right)$ & $\mathrm{T}(\mathrm{K})$ & $\mathrm{E} / \mathrm{N}(\mathrm{Td})$ \\
\hline $0.0 \mathrm{~km}$ & $2.55 \times 10^{25}$ & 288.15 & $5.0 \times 10^{-3}$ \\
$5.0 \mathrm{~km}$ & $1.54 \times 10^{25}$ & 255.68 & $1.1 \times 10^{-3}$ \\
$10.0 \mathrm{~km}$ & $8.60 \times 10^{24}$ & 223.25 & $6.0 \times 10^{-4}$ \\
\hline
\end{tabular}

The calculated mobilities of ions are listed in Table 2, together with their molecular weight, the potential parameters, and the experimental values presently available.

According to the IMS experiment carried out by Hõrak et al. (1994), most of the mobility values of negative ions in air are concentrated in the interval of $0.6 \times 10^{-4}$ and $2.5 \times 10^{-4} \mathrm{~m}^{2} \mathrm{~V}^{-1} \mathrm{~s}^{-1}$. The present values are put in this interval except for $\mathrm{NO}_{2}{ }^{-}$. In fact, the $\mathrm{NO}_{2}{ }^{-}$is a daughter (or fragmented) ion observed by the collisional dissociation experiment of tropospheric $\mathrm{NO}_{3}{ }^{-}$ion (Eisele, 1989). So, only this membership may be rather irrelevant.

The drift velocities $U$ and diffusion coefficients $D$ at altitudes of 0.0 $\mathrm{km}, 5.0 \mathrm{~km}$, and $10.0 \mathrm{~km}$ are listed in Table 3 . These are calcualted from Eqs. (3) and (4) using the mobility values listed in Table 2. We find in Table 3 that the overall tendency of $U$ and $D$ in molecular weight as well as in altitude appears to be the same as that of the positive ions (Iinuma and Nishikatsu, 1997). The only difference is that the mean values both of $U$ and $D$ for negative ions are a little smaller than those of positive 
Table 2. Calculated and experimental reduced mobilities of negative ions in the troposphere.

\begin{tabular}{|c|c|c|c|c|c|c|c|}
\hline \multirow[b]{2}{*}{ Ions } & \multirow[b]{2}{*}{ BNI } & \multirow{2}{*}{\multicolumn{2}{|c|}{$\left(\begin{array}{ll}k & a\end{array}\right)$}} & \multirow[b]{2}{*}{$\varepsilon(\mathrm{meV})$} & \multirow[b]{2}{*}{$r_{m}(\AA)$} & \multicolumn{2}{|c|}{$K_{0}\left(\times 10^{-4} m^{2} \gamma^{-1} s^{-1}\right)$} \\
\hline & & & & & & exptl & theorcl \\
\hline $\mathrm{NO}_{2}^{-}$ & 46 & $(17$, & $0.07)$ & 75.0 & 3.7 & 2. 60 a) & 2.58 \\
\hline $\mathrm{C}_{2} \mathrm{H}_{3} \mathrm{O}_{2}^{-}$ & 59 & $(16$, & $0.15)$ & 37.1 & 4.9 & & 2.26 \\
\hline $\mathrm{NO}_{3}-$ & 62 & $(16$, & $0.12)$ & 38.1 & 4.7 & 2. 37 a) & 2.38 \\
\hline $\mathrm{NO}_{3}-\cdot \mathrm{H}_{2} \mathrm{O}$ & 80 & & "I & 32.3 & 4.9 & & 2.32 \\
\hline $\mathrm{CH}_{3} \mathrm{SO}_{3}^{--}$ & 95 & (16. & $0.15)$ & 29.2 & 5.2 & & 2.14 \\
\hline $\mathrm{HSO}_{4}^{-}$ & 97 & $(16$, & $0.12)$ & 35.0 & 4.8 & & 2.26 \\
\hline $\mathrm{C}_{3} \mathrm{H}_{3} \mathrm{O}_{4}^{-}$ & 103 & $(16$. & $0.15)$ & 23.3 & 5.5 & & 2.12 \\
\hline $\mathrm{NO}_{3}-\cdot \mathrm{BNO}_{3}$ & 125 & & 11 & 17.6 & 5.9 & 2. $05 \mathrm{a})$ & 2.05 \\
\hline $\mathrm{NO}_{2} \cdot \mathrm{SO}_{4}^{-}$ & 142 & & $" \prime$ & 16.5 & 6.0 & & 2.02 \\
\hline $\mathrm{NO}_{3}-\cdot \mathrm{HNO}_{3} \cdot \mathrm{H}_{2} \mathrm{O}$ & 143 & & $" \prime$ & 14.5 & 6.2 & & 1.99 \\
\hline$\left(\mathrm{NO}_{3} \cdot \mathrm{HSO}_{3}\right)^{-}$ & 143 & & $" \prime$ & 15.4 & 6.1 & & 2.00 \\
\hline $\mathrm{HSO}_{4}^{-} \cdot \mathrm{HNO}_{3}$ & 160 & & $" \prime$ & 13.6 & 6.3 & & 1.95 \\
\hline $\mathrm{NO}_{3}-\cdot \mathrm{HNO}_{3} \cdot\left(\mathrm{H}_{2} \mathrm{O}\right)_{2}$ & 161 & & $"$ & 12.0 & 6.5 & & 1.91 \\
\hline $\mathrm{NO}_{3}-\cdot \mathrm{HNO}_{3} \cdot \mathrm{HCl}$ & 161.5 & & $" 1$ & 12.7 & 6.4 & & 1.93 \\
\hline $\mathrm{C}_{3} \mathrm{H}_{3} \mathrm{O}_{4}-\cdot \mathrm{HNO}_{3}$ & 166 & $(15$, & $0.18)$ & 15.1 & 6.4 & & 1.82 \\
\hline $\mathrm{NO}_{3}-\cdot\left(\mathrm{HNO}_{3}\right)_{2}$ & 188 & & $" 1$ & 14.2 & 6.5 & 1. 79 a). & 1.79 \\
\hline $\mathrm{HSO}_{4}-\cdot \mathrm{H}_{2} \mathrm{SO}_{4}$ & 195 & & $" \prime$ & 15.1 & 6.4 & & 1.80 \\
\hline $\mathrm{NO}_{3}-\cdot\left(\mathrm{ENO}_{3}\right)_{2} \cdot \mathrm{H}_{2} \mathrm{O}$ & 206 & & $" \prime$ & 13.4 & 6.6 & & 1.76 \\
\hline $\mathrm{HSO}_{4}-\cdot \mathrm{HSO}_{5}$ & 210 & & $" \prime$ & 14.2 & 6.5 & & 1.76 \\
\hline $\mathrm{HSO}_{4}-\cdot \mathrm{H}_{2} \mathrm{SO}_{4} \cdot \mathrm{H}_{2} \mathrm{O}$ & 213 & & $"$ & 11.9 & 6.8 & & 1.72 \\
\hline $\mathrm{HSO}_{4}-\cdot\left(\mathrm{HNO}_{3}\right)_{2}$ & 223 & & " & 10.6 & 7.0 & & 1.68 \\
\hline $\mathrm{HSO}_{4}-\cdot\left(\mathrm{ENO}_{3}\right)_{2} \cdot \mathrm{H}_{2} \mathrm{O}$ & 241 & (14. & $0.20)$ & 10.9 & 7.2 & & 1.58 \\
\hline $\mathrm{HSO}_{4}-\cdot \mathrm{HSO}_{3} \cdot \mathrm{HNO}_{3}$ & 241 & & " & 11.5 & 7.1 & & 1.59 \\
\hline $\mathrm{NO}_{3}-\left(\mathrm{HNO}_{3}\right)_{3}$ & 251 & & $" 1$ & 10.9 & 7.2 & & 1.58 \\
\hline $\mathrm{NO}_{3}-\cdot\left(\mathrm{HNO}_{3}\right)_{3} \cdot \mathrm{H}_{2} \mathrm{O}$ & 269 & & $"$ & 10.3 & 7.3 & & 1.56 \\
\hline $\mathrm{HSO}_{4}-\cdot \mathrm{HSO}_{5} \cdot \mathrm{HNO}_{3}$ & 273 & & $" \prime$ & 9.2 & 7.5 & & 1.52 \\
\hline $\mathrm{HSO}_{4}-\cdot \mathrm{H}_{2} \mathrm{SO}_{4} \cdot \mathrm{HNO}_{3} \cdot \mathrm{H}_{2} \mathrm{O}$ & 276 & & $"$ & 8.7 & 7.6 & & 1.50 \\
\hline $\mathrm{HSO}_{4}-\cdot\left(\mathrm{HNO}_{3}\right)_{3}$ & 286 & & $"$ & 8.7 & 7.6 & & 1.50 \\
\hline $\mathrm{HSO}_{4}^{-} \cdot\left(\mathrm{H}_{2} \mathrm{SO}_{4}\right)_{2}$ & 293 & & $" 1$ & 7.9 & 7.8 & & 1.46 \\
\hline $\mathrm{HSO}_{4}-\cdot\left(\mathrm{H}_{2} \mathrm{SO}_{4}\right)_{2} \cdot \mathrm{HNO}_{3}$ & 356 & & $" \prime$ & 7.5 & 7.9 & & 1.43 \\
\hline
\end{tabular}

a) Böhringer et al., 1987 
Table 3. Calculated drift velocities $U$ and diffusion coefficients $D$ of tropospheric negative ions at three different altitudes. $U$ and $D$ are expressed in the units of $10^{-2} \mathrm{~ms}^{-1}$ and $10^{-4} \mathrm{~m}^{2} \mathrm{~s}^{-1}$, respectively.

\begin{tabular}{|c|c|c|c|c|c|c|c|}
\hline \multirow[b]{2}{*}{ Ions } & \multirow[b]{2}{*}{ MT } & \multicolumn{2}{|c|}{ alt. $=0.0 \mathrm{~km}$} & \multicolumn{2}{|c|}{ alt $=5.0 \mathrm{kma}$} & \multicolumn{2}{|c|}{ alt. $=10.0 \mathrm{~km}$} \\
\hline & & u & D & U & D & $U$ & D \\
\hline $\mathrm{NO}_{2}^{-}$ & 46 & 3.47 & 0.067 & 0.76 & 0.099 & 0.42 & 0.155 \\
\hline $\mathrm{C}_{2} \mathrm{H}_{3} \mathrm{O}_{2}^{-}$ & 59 & 3.04 & 0.059 & 0.67 & 0.087 & 0.36 & 0.136 \\
\hline $\mathrm{NO}_{3}^{-}$ & 62 & 3.20 & 0.062 & 0.70 & 0.091 & 0.38 & 0.143 \\
\hline $\mathrm{NO}_{3}-\cdot \mathrm{H}_{2} \mathrm{O}$ & 80 & 3.12 & 0.061 & 0.69 & 0.089 & 0.37 & 0.139 \\
\hline $\mathrm{CH}_{3} \mathrm{SO}_{3}^{-}$ & 95 & 2.87 & 0.056 & 0.63 & 0.082 & 0.34 & 0.129 \\
\hline $\mathrm{HSO}_{4}^{-}$ & 97 & 3.04 & 0.059 & 0.67 & 0.087 & 0.36 & 0.136 \\
\hline $\mathrm{C}_{3} \mathrm{H}_{3} \mathrm{O}_{4}^{-}$ & 103 & 2.85 & 0.055 & 0.63 & 0.081 & 0.34 & 0.127 \\
\hline $\mathrm{NO}_{3}-\cdot \mathrm{HNO}_{3}$ & 125 & 2.75 & 0.054 & 0.61 & 0.079 & 0.33 & 0.123 \\
\hline $\mathrm{NO}_{2} \cdot \mathrm{SO}_{4}^{-}$ & 142 & 2.71 & 0.053 & 0.60 & 0.078 & 0.33 & 0.121 \\
\hline $\mathrm{NO}_{3}-\cdot \mathrm{HNO}_{3} \cdot \mathrm{H}_{2} \mathrm{O}$ & 143 & 2.67 & 0.052 & 0.59 & 0.076 & 0.32 & 0.120 \\
\hline$\left(\mathrm{NO}_{3} \cdot \mathrm{HSO}_{3}\right)^{-}$ & 143 & 2.69 & 0.052 & 0.59 & 0.077 & 0.32 & 0.120 \\
\hline $\mathrm{HSO}_{4}^{-} \cdot \mathrm{HNO}_{3}$ & 160 & 2.62 & 0.051 & 0.58 & 0.075 & 0.31 & 0.117 \\
\hline $\mathrm{NO}_{3}-\cdot \mathrm{HNO}_{3} \cdot\left(\mathrm{H}_{2} \mathrm{O}\right)_{2}$ & 161 & 2.57 & 0.050 & 0.56 & 0.073 & 0.31 & 0.115 \\
\hline $\mathrm{NO}_{3}^{-} \cdot \mathrm{HNO}_{3} \cdot \mathrm{HCl}$ & 161.5 & 2.59 & 0.050 & 0.57 & 0.074 & 0.31 & 0.116 \\
\hline $\mathrm{C}_{3} \mathrm{H}_{3} \mathrm{O}_{4}-\cdot \mathrm{HNO}_{3}$ & 166 & 2.44 & 0.048 & 0.54 & 0.070 & 0.29 & 0.109 \\
\hline $\mathrm{NO}_{3}-\cdot\left(\mathrm{HNO}_{3}\right)_{2}$ & 188 & 2. 40 & 0.047 & 0.53 & 0.069 & 0.29 & 0.108 \\
\hline $\mathrm{HSO}_{4}-\cdot \mathrm{H}_{2} \mathrm{SO}_{4}$ & 195 & 2. 42 & 0.047 & 0.53 & 0.069 & 0.29 & 0.108 \\
\hline $\mathrm{NO}_{3}^{-} \cdot\left(\mathrm{HNO}_{3}\right)_{2} \cdot \mathrm{H}_{2} \mathrm{O}$ & 206 & 2. 36 & 0.046 & 0.52 & 0.068 & 0.28 & 0.106 \\
\hline $\mathrm{HSO}_{4}-\cdot \mathrm{HSO}_{5}$ & 210 & 2.36 & 0.046 & 0.52 & 0.068 & 0.28 & 0.106 \\
\hline $\mathrm{HSO}_{4}^{-} \cdot \mathrm{H}_{2} \mathrm{SO}_{4} \cdot \mathrm{H}_{2} \mathrm{O}$ & 213 & 2. 31 & 0.045 & 0.51 & 0.066 & 0.28 & 0.103 \\
\hline $\mathrm{HSO}_{4}-\cdot\left(\mathrm{HNO}_{3}\right)_{2}$ & 223 & 2.26 & 0.044 & 0.50 & 0.065 & 0.27 & 0.101 \\
\hline $\mathrm{HSO}_{4}-\cdot\left(\mathrm{HNO}_{3}\right)_{2} \cdot \mathrm{H}_{2} \mathrm{O}$ & 241 & 2.12 & 0.041 & 0.47 & 0.061 & 0.25 & 0.095 \\
\hline $\mathrm{HSO}_{4}-\cdot \mathrm{HSO}_{3} \cdot \mathrm{HNO}_{3}$ & 241 & 2.14 & 0.042 & 0.47 & 0.061 & 0.26 & 0.096 \\
\hline $\mathrm{NO}_{3}-\cdot\left(\mathrm{HNO}_{3}\right)_{3}$ & 251 & 2. 12 & 0.041 & 0.47 & 0.061 & 0.25 & 0.095 \\
\hline $\mathrm{NO}_{3}-\cdot\left(\mathrm{HNO}_{3}\right)_{3} \cdot \mathrm{H}_{2} \mathrm{O}$ & 269 & 2.10 & 0.041 & 0.46 & 0.060 & 0.25 & 0.094 \\
\hline $\mathrm{HSO}_{4}-\cdot \mathrm{HSO}_{5} \cdot \mathrm{HNO}_{3}$ & 273 & 2.04 & 0.040 & 0.45 & 0.058 & 0.25 & 0.091 \\
\hline $\mathrm{HSO}_{4}-\cdot \mathrm{H}_{2} \mathrm{SO}_{4} \cdot \mathrm{HNO}_{3} \cdot \mathrm{H}_{2} \mathrm{O}$ & 276 & 2.01 & 0.039 & 0.44 & 0.058 & 0.24 & 0.090 \\
\hline $\mathrm{HSO}_{4}^{-} \cdot\left(\mathrm{HNO}_{3}\right)_{3}$ & 286 & 2. 01 & 0.039 & 0.44 & 0.058 & 0.24 & 0.090 \\
\hline $\mathrm{HSO}_{4}^{-} \cdot\left(\mathrm{H}_{2} \mathrm{SO}_{4}\right)_{2}$ & 293 & 1.96 & 0.038 & 0.43 & 0.056 & 0.24 & 0.088 \\
\hline $\mathrm{HSO}_{4}-\cdot\left(\mathrm{H}_{2} \mathrm{SO}_{4}\right)_{2} \cdot \mathrm{HNO}_{3}$ & 356 & 1.92 & 0.037 & 0.42 & 0.055 & 0.23 & 0.086 \\
\hline
\end{tabular}


ions. This indicates that the mean molecular weight of the negative ions identified so far is much heavier than the positive ions. It is commonly known, however, that the mean drift velocity of positive ions is lower than the negative ions in the atmosphere (Horrak et al., 1994; Knudsen and Israelsson, 1994). This contradiction suggests that a large number of much heavier positive ion clusters and aerosol particles, which are not yet precisely identified, are still present. The molcular weight of those ions may exceed far more than 500 amu.

Finally, we derive a pair of useful formulae to obtain the forward and the reverse reaction rate of clustering reactions in dynamic equilibrium (Iinuma et al., 1993). In dynamic equilibrium, all the ionic species reaches a stable state because of the dynamic balance between their transport processes and all ion/molecule reactions occurring in the system. However, every ion is still drifting, diffusing, and reacting with ambient molecules under the influence of outer electric field.

When two ionic species $X$ and $Y$ satisfy this balance condition, an equilibrium of forward and reverse reaction is attainable;

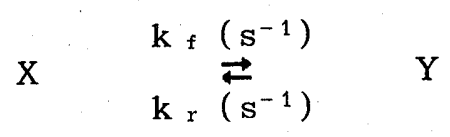

where $k_{f}$ and $k_{r}$ are the forward and the reverse reaction rate. To obtain the transport coefficients and reaction rate constants of $X$ and $Y$, we can resort to the solution of coupled diffusion-reaction equations for multiple $i$ on swarms. If no reaction of Eq. (5) occurs, $X$ and $Y$ are simply drifting and diffusing independently so that we must observe two separated pure Gaussian-type arrival time spectra (ATS). However, when the reactive ion transport attains a dynamic balance, the profile of their ATS will change markedly. Figure 1 shows it; the both spectra (two solid curves: $X$ and $Y$ ) appear to be almost same Gaussian profile with the same peak position (around $\beta$ ) and the same FWHM $\gamma$, except for their spectrum area (a slight difference of two peak positions $\delta$ in Figl. 1 is neglected at present, while the difference is essentially important for precise determination of the transport coefficients and reaction rates: Iinuma et al. 1994). We now focus on the $X+Y$ spectrum (the dashed curve: the sum of $X$ and $Y$ ), which also displays the same Gaussian profile with the same peak position $\beta$, and the same FWHM $\gamma$. According to the dynamic equilibrium theory (Iinuma et al., 1994), the $X+Y$ spectrum is represented by the mean drift velocity $U_{e}^{\prime}$ and the mean diffusion coefficient $D_{e}$;

$$
\begin{aligned}
& U_{e}=\frac{k_{r} U_{1}+k_{f} U_{2}}{k_{f}+k_{r}} \\
& D_{e}=\frac{k_{r} D_{1}+k_{f} D_{2}}{k_{f}+k_{r}}+\frac{k_{f} k_{r}\left(U_{1}-U_{2}\right)^{2}}{\left(k_{f}+k_{r}\right)^{3}}
\end{aligned}
$$

where $U_{1}$ and $U_{2}$ are the drift velocities of $X$ and $Y$, and $D_{1}$ and $D_{2}$ 
are their diffusion coefficients. It is noted that $U_{e}$ and $D_{e}$ are measurable in drift-tube experiment without mass spectrometer, because these two values can simply be determined from $\beta$ and $\gamma$ of the $X+Y$ ATS using

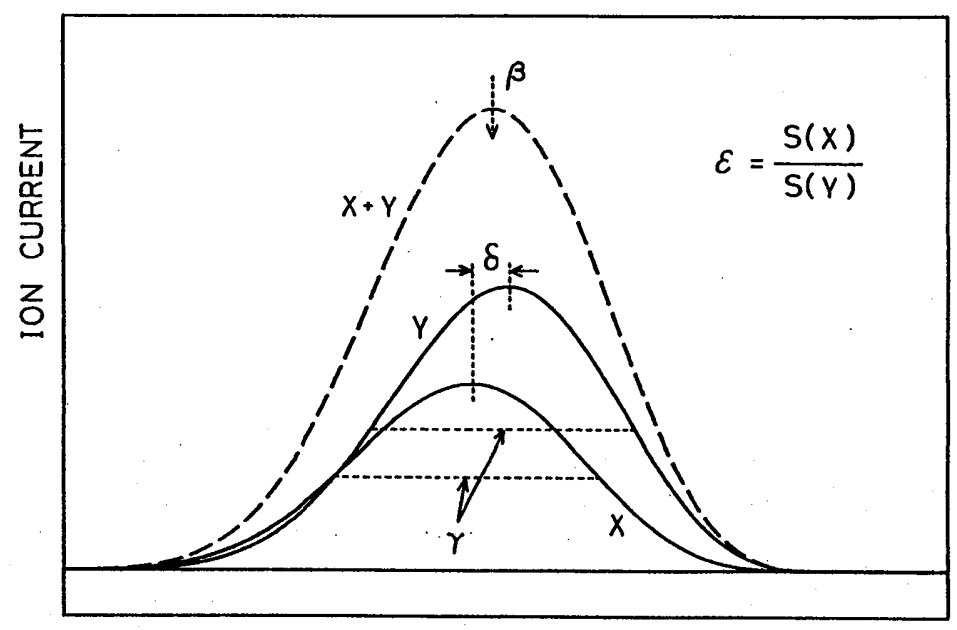

DRIFT TIME

Fig. 1. Arrival time spectra of $X$ and $Y$ in dynamic equilibrium, which are numerically obtained from the solution of coupled diffusionreaction equations for two ionic species (two solid curves). A dashed curve is the ATS produced by adding $X$ and $Y$ at the same elapsed time. $\quad \beta$, the peak position of $X+Y$ spectrum: $\gamma$, the FWHM of all spectra: $\delta$, the peak difference between $X$ and $Y$ : $\varepsilon$, the area ratio of $X$ and $Y$.

the drift distance employed in the measurement. Then, Eqs (6) and (7) allow for us to derive $\mathrm{k}_{f}$ and $\mathrm{k}_{r}$ as

$$
\begin{aligned}
& k_{f}=\frac{A_{1}{ }^{2} \cdot A_{4}}{\left(1+A_{1}\right)^{2}\left(A_{2}+A_{1} \cdot A_{3}\right)} \\
& k_{r}=\frac{A_{1} \cdot A_{4}}{\left(1+A_{1}\right)^{2}\left(A_{2}+A_{1} \cdot A_{3}\right)}
\end{aligned}
$$


where

$$
\begin{cases}A_{1}=\frac{U_{1}-U_{e}}{U_{e}-U_{2}}, & A_{2}=\frac{D_{e}-D_{1}}{D_{e}} \\ A_{3}=\frac{D_{e}-D_{2}}{D_{e}}, & A_{4}=\frac{\left(U_{1}-U_{2}\right)^{2}}{D_{e}}\end{cases}
$$

The values $U_{1}, U_{2}, D_{1}$, and $D_{2}$ may be available in Table 3 .

Although the accurate determination of $U_{e}$ and $D_{e}$ by drift-tube experiments appears, in general, to be rather formidable, the following precaution and an additional measurement technique may be helpful; (1) Check the form of the measured ATS which should attain a Gaussian-type profile. (2) To confirm the ionic species constituting the ATS, it is much better to identify the presented ions using mass spectrometry.

To the best of our knowledge, however, no experimental ATS data appropriate for present analysis are available so far. We therefore test the soundness of Eqs. (8)-(10) by employing a hypothetical data set of $\mathrm{HSO}_{4}^{-}$. $\mathrm{HNO}_{3}$ and $\mathrm{HSO}_{4}-\left(\mathrm{HNO}_{3}\right)_{2}$ ion clusters at the ground level:

$$
\mathrm{HSO}_{4}-\mathrm{HNO}_{3}+\mathrm{HNO}_{3}+\mathrm{M} \underset{\mathrm{kr}_{\mathrm{r}}}{\stackrel{\mathrm{kf}}{\rightleftarrows}} \quad \mathrm{HSO}_{4}^{-} \cdot\left(\mathrm{HNO}_{3}\right)_{2}+\mathrm{M}
$$

According to a model of tropospheric negative ion chemistry developed by Kawamoto and 0 gawa $(1986)$, the $\mathrm{HSO}_{4}-\left(\mathrm{HNO}_{3}\right)_{\mathrm{n}}$ ion-cluster family is originated only from the forward reaction of $\mathrm{NO}_{3}^{-} \cdot\left(\mathrm{HNO}_{3}\right)_{n}$ family with a $\mathrm{H}_{2} \mathrm{SO}_{4}$ molecule. This scheme suggests that a seires of $\mathrm{HSO}_{4}^{-} \cdot\left(\mathrm{HNO}_{3}\right)_{\mathrm{n}}$ ions constitutes one terminal-ion-familiy, which appears to be much more stable chemically than other negative ion clusters in the troposphere.

In Table 3, we find the drift velocities and diffusion coefficients of $\mathrm{HSO}_{4}-\mathrm{HNO}_{3}$ ( (suffix No. 1) and $\mathrm{HSO}_{4}^{-} \cdot\left(\mathrm{HNO}_{3}\right)_{2}$ (suffix No. 2); $\mathrm{U}_{1}=2.62 \times 10^{-2}$ $\mathrm{ms}^{-1}, \quad \mathrm{U}_{2}=2.26 \times 10^{-2} \mathrm{~ms}^{-1}, \quad \mathrm{D}_{1}=5.1 \times 10^{-6} \mathrm{~m}^{2} \mathrm{~s}^{-1}, \quad$ and $\mathrm{D}_{2}=4.4 \times 10^{-6} \mathrm{~m}^{2} \mathrm{~s}^{-1}$. In the equilibrium attained by Eq. (11), it is possible to measure the ATS, which will display a Gaussian profile like the dashed ATS in Fig. 1. From its $\beta$ and $\gamma$ we can determine the values of $U_{e}$ and $D_{e}$, for example, to be $2.277 \times 10^{-2} \mathrm{~ms}^{-1}$ and $4.433 \times 10^{-6} \mathrm{~m}^{2} \mathrm{~s}^{-1}$. Making use of these values, Eqs. (8) $-(10)$ result $\mathrm{k}_{f}=3640 \mathrm{~s}^{-1}$ and $\mathrm{k}_{\mathrm{r}}=180 \mathrm{~s}^{-1}$. The corresponding values cited commonly in atmospheric chemistry are $2600 \mathrm{~s}^{-1}$ and $130 \mathrm{~s}^{-1}$, respectively (for example, Kawamoto and Ogawa, 1986). Natural concentrations of $\mathrm{HNO}_{3}$ and air [M in Eq. (11)] employed are $1.0 \times 10^{16} \mathrm{~m}^{-3}$ and $2.55 \times 10^{25} \mathrm{~m}^{-3}$, respectively (Luts and Salm, 1994). Again, it should be emphasized that this analysis is based upon a hypothetical data set of $U_{e}$ and $D_{e}$, but the general soundness of Eqs. $(8)-(10)$ has been justified.

4. Conclusions

The drift velocities and diffusion coefficients of 30 tropospheric negative ions are calculated at three different altitudes. Their overall 
tendency in molecular weight as well as in altitude is the same as that of positive ions. However, their mean values are a little smaller than positive-ion group. By employing dynamic equilibrium condition in the troposphere, the forward and reverse reaction rates of $\mathrm{HSO}_{4}^{-} \cdot\left(\mathrm{HNO}_{3}\right)_{\mathrm{n}}(\mathrm{n}=1,2)$ are estimated from their drift velocities and diffusion coefficients.

Acknowledgements. The author is greatful to Dr. M. Takebe and Dr. M. 0kamoto for their generous encouragement.

\section{References}

Böhringer, H. , D. W. Fahey, W. Lindinger, F. Howorka, F. C. Fehsenfeld, and D. L. Albritton, Mobilities of several mass-identified positive and negative ions in air, Int. J. Mass Spectrom. Ion Processes 81, 45-65, 1987.

Eisele, F. L., Natural and anthropogenic negative ions in the troposphere, J. Geophys. Res. 94, 2183-2196, 1989.

Heitmann, H. and F. Arnold, Composition measurements of tropospheric ions, Nature 306, 747-751, 1983.

Hirschfelder, J. 0., C. F. Curtiss, and R. B. Bird, Molecular Theory of Gases and Liquids, pp. 1249, Wiley, New York, 1964.

Hôrrak, U., H. Iher, A. Luts, J. Salm, and H. Tammet, Mobility spectrum of air ions at Tahkuse observatory, J. Geophys. Res. 99, 10697-10700, 1994.

Iinuma, K., N. Sasaki, and M. Takebe, A general analysis of reactive ion transport in dynamic equilibrium, J. Chem. Phys. 99, 6907-6914, 1993.

Iinuma, K., and H. Nishikatsu, A model calculation of transport coefficient for small positive ions in the troposphere, J. Atmos. Electr., 17, $11-22,1997$.

Iinuma, K., H. Hamano, and M. Takebe, Analysis of two ion swarms in dynamic equilibrium: Simultaneous determination of two drift velocities and two reaction frequencies, J. Chem. Phys. 101, 2949-2952, 1994.

Kawamoto, H., and T. Ogawa, First model of negative ion composition in the troposphere, Planet. Space Sci. 34, 1229-1239, 1986.

Knudsen, E., and S. Israelsson, Method of measuring the mobility spectrum versus ageing of atmospheric ions, J. Geophys. Res. 모, 22767-22771, 1994.

Luts, A., and J. Salm, Chemical composition of small atmospheric ions near the ground, J. Geophys. Res. 99, 10781-10785, 1994.

Mason, E. A., and E. W. McDaniel, Transport Properties of Ions in Gases, pp. 560, Wiley, New York, 1988.

Radzig, A. A., and B. M. Smirnov, Reference Data on Atoms, Molecules, and Ions, pp. 463, Springer, Berlin, 1985.

Wahlin, L., Elements of fair weather electricity, J. Geophys. Res. $\underline{99}$, $10767-10772,1994$.

Warneck, P., Chemistry of the Natural Atmosphere, pp. 753, Academic Press, New York, 1988.

(Received December 13, 1997; revised January 16, 1998; accepted January 19, 1998.) 